Int. J. Electrochem. Sci., 15 (2020) 10141 - 10156

International Journal of

ELECTROCHEMICAL

SCIENCE

WWW.electrochemsci.org

\title{
Preparation of a Novel Electrochemical Sensor for Isoniazid Determination
}

\author{
Miao Liu, Mingxuan Jia and Donghui Li* \\ The Center Laboratory of Pharmaceutical analysis, Pharmaceutical College, Jinzhou Medical \\ University, Jinzhou, 121001, P.R.China \\ *E-mail: lidonghuilx@ sina.com
}

doi: $10.20964 / 2020.10 .67$

Received: 6 July 2020 / Accepted: 18 August 2020 / Published: 31 August 2020

\begin{abstract}
This article introduces a new type of method for the content determination of isoniazid (INH) established on the principle of electrochemistry. Polyoxomolybdate, as the electroactive substance, was fixed on the surface of a glassy carbon electrode (GCE) with Nafion solution, so that the electroactive substance was tightly combined with the electrode surface and the electron transfer was enhanced. Based on this technique, a novel type of highly sensitive electrochemical sensor was established. The properties of the electrochemical sensor were characterized by cyclic voltammetry (CV) and differential pulse voltammetry (DPV). The results showed that polyoxomolybdate could contribute to electron transfer on the sensor and had a strong electrocatalytic activity for INH, which greatly improved the sensitivity of the sensor. Under optimized conditions, this method had a good linear range for INH $(0.1 \mu \mathrm{g} / \mathrm{L}$ to 0.3 $\mu \mathrm{g} / \mathrm{L}, \mathrm{R}^{2}=0.9979$ ), and the detection limit (LOD) was $0.024 \mu \mathrm{g} / \mathrm{L}$. The sensor showed excellent performance in terms of repeatability and lifetime. In addition, the stable crystal structure of polyoxomolybdate and the participation of Nafion solution contributed to the stability and reproducibility of the electrochemical behaviour. This method has been used for the successful determination of INH.
\end{abstract}

Keywords: Polyoxomolybdate; Electrochemical sensor; Detection method; Isoniazid

\section{FULL TEXT}

(C) 2020 The Authors. Published by ESG (www.electrochemsci.org). This article is an open access article distributed under the terms and conditions of the Creative Commons Attribution license (http://creativecommons.org/licenses/by/4.0/). 